Case Study

\title{
Ankle inversion taping using kinesiology tape for treating medial ankle sprain in an amateur soccer player
}

\author{
Sun-Min Lee, PhD, PT ${ }^{1)}$, Jung-Hoon Lee, PhD, $\mathrm{PT}^{2)^{*}}$ \\ 1) Department of Occupational Therapy, College of Rehabilitation Science, Daegu University, Republic \\ of Korea \\ 2) Department of Physical Therapy, College of Nursing and Healthcare Sciences, Dong-Eui University: \\ 176 Eomgwangno, Busanjin-gu, Busan 614-714, Republic of Korea
}

\begin{abstract}
Purpose] The purpose of this study was to report the effects of ankle inversion taping using kinesiology tape in a patient with a medial ankle sprain. [Subject] A 28-year-old amateur soccer player suffered a Grade 2 medial ankle sprain during a match. [Methods] Ankle inversion taping was applied to the sprained ankle every day for 2 months. [Results] His symptoms were reduced after ankle inversion taping application for 2 months. The self-reported function score, the reach distances in the Star Excursion Balance Test, and the weight-bearing ankle dorsiflexion were increased. [Conclusion] This study showed that ankle inversion taping using kinesiology tape may be an effective therapy for a patient with a medial ankle sprain.

Key words: Cumberland Ankle Instability Tool, Eversion ankle sprain, Star Excursion Balance Test
\end{abstract}

(This article was submitted Mar. 9, 2015, and was accepted Apr. 13, 2015)

\section{INTRODUCTION}

Ankle sprain is a common sport-related injury ${ }^{1)}$. This type of injury involves stretching and tearing of the ankle ligaments. Approximately $85 \%$ of all ankle sprains are related to the lateral ligament complex ${ }^{2}$. Medial ankle sprains are somewhat rare, accounting for approximately $10-15 \%$ of all ankle sprains in athletes, and can result in long-term disability ${ }^{3)}$. Most of the pain and tenderness caused by a medial ankle sprain is localized to the medial aspect of the ankle, especially around the deltoid ligament and the medial malleolus.

Majority of the existing studies are on lateral ankle sprains ${ }^{4}$. Here, we report the effects of ankle inversion taping (AIT) using kinesiology tape in a patient with a medial ankle sprain.

\section{SUBJECT AND METHODS}

A 28-year-old amateur soccer player complained of severe pain on the medial aspect of his left ankle after sustaining a Grade 2 medial ankle sprain during a soccer match one month prior to his visit. He presented with a history of left ankle injury 3 years ago, following which, his ankle was

*Corresponding author. Jung-Hoon Lee (E-mail: dreampt@ hanmail.net)

(C2015 The Society of Physical Therapy Science. Published by IPEC Inc. This is an open-access article distributed under the terms of the Creative Commons Attribution Non-Commercial No Derivatives (by-ncnd) License $<$ http://creativecommons.org/licenses/by-nc-nd/3.0/>. in a cast for 3 weeks. He experienced painful eversion and dorsiflexion of the left ankle and severe pain during sportrelated activities such as jumping and turning. In particular, full weight bearing on the left leg was difficult because of severe pain. Prior to participation in this study, the patient demonstrated an understanding of the study purpose and provided written informed consent. This protocol was in accordance with the ethical standards of the Declaration of Helsinki.

In the initial assessment, the tenderness on the medial aspect of the ankle, at a pressure of $3 \mathrm{~kg}$, was measured using an algometer (Pain Test-Model FPK; Wagner Instruments, Greenwich, CT, USA) on a $0-10$ scale, with 0 indicating no pain and 10 indicating the worst pain ${ }^{5)}$. The tenderness at $3 \mathrm{~kg}$ was 8 .

The patient's self-reported functional ankle deficits using the Cumberland Ankle Instability Tool (CAIT) questionnaire, which is comprised of 9 items scored on a 30-point scale ${ }^{6)}$, were investigated. The CAIT score of his left ankle was $11 / 30$.

Dynamic balance was assessed using the Star Excursion Balance Test (SEBT) $)^{7}$. The SEBT is a valid and reliable tool for dynamic postural control assessment of subjects with ankle instability ${ }^{8}$. The maximal reach distances of the opposite leg in the anterior, posteromedial, and posterolateral directions when standing on the sprained leg were $57 \mathrm{~cm}$, $60.5 \mathrm{~cm}$, and $65.5 \mathrm{~cm}$, respectively.

Ankle flexibility was assessed using weight-bearing ankle dorsiflexion (the distance from big toe to wall in maximal ankle dorsiflexion with knee flexion without lifting the heel) was assessed ${ }^{9}$. The initial distance was $2.6 \mathrm{~cm}$.

At the initial ankle active range of motion assessment, the 
eversion, inversion, plantarflexion, and dorsiflexion ranges of the left ankle were $6^{\circ} / 20^{\circ}, 25^{\circ} / 45^{\circ}, 46^{\circ} / 60^{\circ}$, and $14^{\circ} / 30^{\circ}$, respectively.

AIT using kinesiology tape (BB TAPE, WETAPE Co., Ltd., Seoul, Korea) was applied to the sprained ankle every day for 2 months. The first I-shaped tape was applied from the talus to the calcaneus in a minimal dorsiflexion position for assisting posterior talar glide (Fig. 1A). The second I-shaped tape was applied from $1-2 \mathrm{~cm}$ above the medial malleolus, over the lateral calcaneus, to the outside of the instep of the foot in a maximal inversion position for assisting ankle inversion and preventing painful eversion (Fig. $1 \mathrm{~B}, \mathrm{C})$. The third I-shaped tape was reapplied in a similar manner as the second step for reinforcement (Fig. 1D, E). The fourth I-shaped tape was reapplied in a similar manner as the first step to reinforce the posterior talar glide (Fig. $1 \mathrm{~F})$. We reapplied AIT to the sprained ankle every day after removal of the previously applied AIT even if the patient did not report any itching and instructed the patient to remove the tape immediately if itching was experienced. In addition, to prevent skin problems, no stretch was applied to the start and end points of approximately $4-5 \mathrm{~cm}$ when the I-shaped tape was applied ${ }^{10)}$. The patient did not undergo any other interventions for treatment of the medial ankle sprain.

\section{RESULTS}

At the final assessment, the tenderness at $3 \mathrm{~kg}$ of pressure decreased from 8 to 1 , and the CAIT score increased from $11 / 30$ to $27 / 30$. The maximal reach distances in the anterior, posteromedial, and posterolateral directions increased from $57 \mathrm{~cm}$ to $72 \mathrm{~cm}$, from $60.5 \mathrm{~cm}$ to $86 \mathrm{~cm}$, and from $65.5 \mathrm{~cm}$ to $87 \mathrm{~cm}$, respectively. The maximal distance of weightbearing ankle dorsiflexion increased from $2.6 \mathrm{~cm}$ to $7.0 \mathrm{~cm}$. The eversion, inversion, dorsiflexion, and plantarflexion range of motion increased from $6^{\circ} / 20^{\circ}$ to $20^{\circ} / 20^{\circ}$, from $25^{\circ} / 45^{\circ}$ to $42^{\circ} / 45^{\circ}$, from $14^{\circ} / 30^{\circ}$ to $28^{\circ} / 30^{\circ}$, and from $46^{\circ} / 60^{\circ}$ to $57^{\circ} / 60^{\circ}$, respectively. Following this treatment, the patient did not experience any medial ankle pain during sport-related activities such as jumping, turning, and was able to perform full weight-bearing on the left leg.

\section{DISCUSSION}

This study showed that the AIT application for 2 months decreased medial ankle pain and the self-reported functional ankle deficits, and it improved the ankle range of motion and dynamic balance. The first treatment strategy with AIT application is protection of the sprained ankle from further injury and avoidance of eversion that can cause pain due to the mechanical effects of inversion. Painful eversion and dorsiflexion of the sprained ankle were avoided through a more inverted ankle with the application of the kinesiology tape. Although no research on the ankle joint has been reported, previous studies have reported on the application of kinesiology tape to support joint structure ${ }^{11)}$ and modified joint structure such as mechanical effect ${ }^{12)}$. We assume that the recurrence of ankle sprain and motions that cause medial ankle pain were avoided. Therefore, the natural healing process of the ankle sprain was assisted.

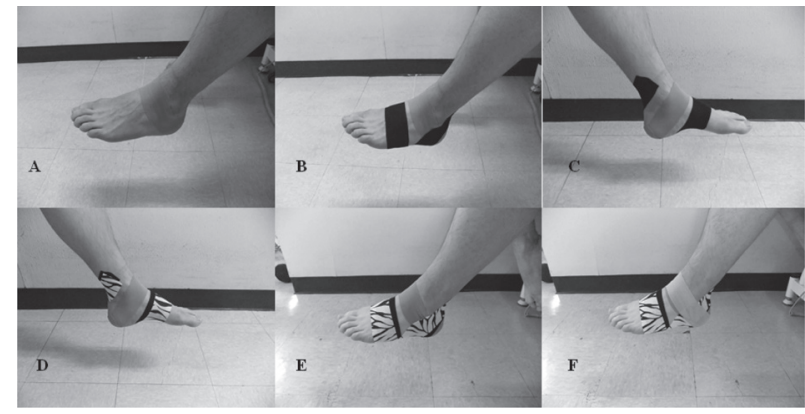

Fig. 1. Ankle inversion taping using kinesiology tape

The kinesiology tape used in this case study stimulates cutaneous mechanoreceptors ${ }^{13)}$ and improves the joint position sense ${ }^{14)}$. The elasticity of the kinesiology tape applied to the skin around the ankle may activate the proprioceptors, while the skin is stretched and shortened during ankle movement. Therefore, maintaining the correct ankle position increased ankle stability, which resulted in an increase in the distances of the SEBT and weight-bearing ankle dorsiflexion. Future mechanical studies on AIT using kinesiology tape in patients with medial ankle sprain are needed.

\section{REFERENCES}

1) Hootman JM, Dick R, Agel J: Epidemiology of collegiate injuries for 15 sports: summary and recommendations for injury prevention initiatives. $\mathrm{J}$ Athl Train, 2007, 42: 311-319. [Medline]

2) Beynnon BD, Murphy DF, Alosa DM: Predictive factors for lateral ankle sprains: A Literature Review, 2002, 37: 376-380.

3) Fallat L, Grimm DJ, Saracco JA: Sprained ankle syndrome: prevalence and analysis of 639 acute injuries. J Foot Ankle Surg, 1998, 37: 280-285. [Medline] [CrossRef]

4) Waterman BR, Belmont PJ Jr, Cameron KL, et al.: Epidemiology of ankle sprain at the United States Military Academy. Am J Sports Med, 2010, 38: 797-803. [Medline] [CrossRef]

5) Rompe JD, Furia J, Maffulli N: Eccentric loading compared with shock wave treatment for chronic insertional achilles tendinopathy. A randomized, controlled trial. J Bone Joint Surg Am, 2008, 90: 52-61. [Medline] [CrossRef]

6) Hiller CE, Refshauge KM, Bundy AC, et al.: The Cumberland ankle instability tool: a report of validity and reliability testing. Arch Phys Med Rehabil, 2006, 87: 1235-1241. [Medline] [CrossRef]

7) Gribble PA, Hertel J: Considerations for normalizing measures of the Star Excursion Balance Test. Meas Phys Educ Exerc Sci, 2003, 7: 89-100. [CrossRef]

8) Hertel J, Miller SJ, Denegar CR: Intratester and intertester reliability during the Star Excursion Balance Tests. J Sport Rehabil, 2000, 9: 104-116.

9) Bennell KL, Talbot RC, Wajswelner H, et al.: Intra-rater and inter-rater reliability of a weight-bearing lunge measure of ankle dorsiflexion. Aust $\mathrm{J}$ Physiother, 1998, 44: 175-180. [Medline] [CrossRef]

10) Kim BJ, Lee JH: Effects of scapula-upward taping using kinesiology tape in a patient with shoulder pain caused by scapular downward rotation. J Phys Ther Sci, 2015, 27: 547-548. [Medline] [CrossRef]

11) Kim BJ, Lee JH: Efficacy of kinesiology taping for recovery from occupational wrist disorders experienced by a physical therapist. J Phys Ther Sci, 2014, 26: 941-943. [Medline] [CrossRef]

12) Han JT, Lee JH, Yoon CH: The mechanical effect of kinesiology tape on rounded shoulder posture in seated male workers: a single-blinded randomized controlled pilot study. Physiother Theory Pract, 2015, 31: 120125. [Medline] [CrossRef]

13) Yamashiro K, Sato D, Yoshida T, et al.: The effect of taping along forearm on long-latency somatosensory evoked potentials (SEPs): an ERP study. Br J Sports Med, 2011, 45: A9. [CrossRef]

14) Murray H, Husk L: Effect of kinesio taping on proprioception in the ankle. J Orthop Sports Phys Ther, 2001, 31: A-37. 